\title{
Aristotle's Political Justice and the Golden Ratio between the Three Opposing Criteria for the Distribution of Public Goods among Citizens: Freedom, Wealth and Virtue
}

\author{
Maria Antonietta Salamone (D)
}

Citation: Salamone, M.A. Aristotle's Political Justice and the Golden Ratio between the Three Opposing Criteria for the Distribution of Public Goods among Citizens: Freedom, Wealth and Virtue. Philosophies 2021, 6, 96. https://doi.org/10.3390/

philosophies6040096

Academic Editor: Marcin J. Schroeder

Received: 23 October 2021

Accepted: 22 November 2021

Published: 27 November 2021

Publisher's Note: MDPI stays neutral with regard to jurisdictional claims in published maps and institutional affiliations.

Copyright: (C) 2021 by the author. Licensee MDPI, Basel, Switzerland. This article is an open access article distributed under the terms and conditions of the Creative Commons Attribution (CC BY) license (https:// creativecommons.org/licenses/by/ $4.0 /)$.
Department of Philosophy and Society, Complutense University of Madrid, 28040 Madrid, Spain; salamonema@filos.ucm.es

Abstract: In this article, I interpret Book V of the Nicomachean Ethics in which Aristotle presents a geometrical problem to explain which is the Best Criterion for the Distribution of Political and Economic Rights and Duties among Citizens, starting from the empirical evidence that there are three opposing opinions on which is the fairest distribution criterion: for some it is Freedom (Democrats), for others Wealth (Oligarchs), and for others Virtue (Aristocrats). Against the almost unique and most quoted interpretation of the geometrical problem, I present my mathematical solution, which I arrived at thanks to the Doctrine of the Four Causes and the Theory of the Mean. My thesis is that the Mean Term of Distributive Justice is the Golden Ratio between the opposite criteria of distribution, and the unjust distribution is the one that violates this ratio. This solution allows us to understand what is the Rational Principle at the basis of just distribution: that is, Geometrical Equality as opposed to Arithmetical Equality. Indeed, by applying the geometric figure of the Golden Triangle to the different political constitutions, I show, in line with Politics, that the Best Form of Government is the Aristocratic Politeia, i.e., a mixture of Democracy, Oligarchy and Aristocracy.

Keywords: Aristotle's Nicomachean Ethics; Aristotle's Politics; Aristotle's Doctrine of the Four Causes; Aristotle's Theory of the Mean; Aristotle's Distributive Justice; Virtue; Geometrical Equality; Golden Ratio; Aristocratic Politeia

\section{Introduction: The Ethical Problem of Political Justice Revolves around the Dispute over Who Should Govern}

The purpose of this article is to offer a political-mathematical interpretation to one of the most problematic questions of Aristotle's Nicomachean Ethics (Book V, 3): the knowledge of the Mean Term of Distributive Justice. To this end, in fact, Aristotle proposes a geometrical problem to be solved, which starts from the fact that there are at least three contrasting opinions on what should be the best criterion for the distribution of political and economic rights and duties among citizens (in fact, the democrats consider that there is only the value of freedom, the oligarchs that of wealth, and the aristocrats that of virtue). Since it is not possible to reach an agreement among the different opinions, it is necessary to take them all into account, hence the Aristotelian idea of establishing the Mean Term of Distributive Justice with respect to the three extreme criteria.

Most of the moderns scholars, such as R. A. Gauthier and J. Y. Jolif [1], as well as H. Rackham [2], W. D. Ross [3], W. F. R. Hardie [4] and J. Tricot [5], have not been able to identify the geometrical problem posed by Aristotle and, consequently, have not been able to solve it. The mathematical interpretation they gave of the text refers, in fact, to two properties of the proportion, namely, the Componendo property: if $A / B=C / D$, then $(A+B) / B=(C+D) / D$, and the Alternando property: if $A / B=C / D$, then $(A+C) /(B+D)=A / B$. However, this interpretation does not offer any clarification to the political question posed by Aristotle; what it does do is certify that each political regime chooses a single, most valued distributive criterion and applies it proportionally to the citizenry (e.g., in an oligarchic regime, political 
and economic rights are distributed proportionally to wealth, in a democratic regime proportionally to the status of freeman, and so on).

In agreement with H. H. Joachim's commentary [6], I think this interpretation is wrong, since it does not solve the problem geometrically and therefore does not even clarify which is the best Criterion of Distributive Justice according to Aristotle. My thesis $[7,8]$ is that the Mean Term of Distributive Justice is the Golden Ratio between the three opposite Criteria of Distribution (Freedom, Wealth and Virtue) and the unjust distribution is the one that violates this ratio. This solution allows us to understand what is the Rational Principle that underlies the Best Distribution Criterion according to Aristotle: that is, Proportional Equality as opposed to Arithmetical Equality, the only one that allows us to achieve Peace and Harmony among the different social classes (Democrats, Oligarchs and Aristocrats). Indeed, the geometrical figure proposed by Aristotle, the Golden Triangle, indicates that the Golden Ratio harmoniously blends the three opposing Criteria into a unitary whole, so that none of them is more powerful than the others; thus, Freedom is in balance with Wealth, Wealth with Virtue and Virtue with Freedom. However, this does not mean that, in qualitative terms, a hierarchy cannot be established between them, since some political values may be better than others, nobler and more important. Proof of this is that the $\delta \iota \alpha ́ \gamma \rho \alpha \mu \mu \alpha$ (diagram) chosen by Aristotle makes it possible to highlight the distribution criterion preferred by Aristotle, ordering the three in a hierarchical manner. Indeed, if the aim of the best political constitution is the Happy and Self-Sufficient Life in accordance with Virtue, the most important distributive criterion to be taken into account is undoubtedly that of Virtue (this is why I have placed Virtue at the apex of the Golden Triangle). For Aristotle, in fact, the polis must be free and rich but, above all, virtuous. This clarification allows us to understand how to put into practice the Aristotelian political ideal according to which those who are superior in political Virtue should deserve a proportionally greater share of economic and political rights than those who are equal or superior in Wealth or Freedom. This ideal is at the antipodes of Arithmetical Equality, according to which anyone can rule because one is worth one. In fact, if we apply the geometric solution of the Golden Triangle to the different political Constitutions, we show, consistently with Aristotle's Politics, that the Best Form of Government is the Aristocratic Politeia, i.e., a mixture of Democracy, Oligarchy and Aristocracy.

In the first part of the article (Section 2), I set out the terms of the political and mathematical question posed by Aristotle, namely the search for the Mean Term of Distributive Justice, but not before introducing Aristotle's Theory of the Mean, which is necessary to solve the geometrical problem. Next, I state the theorem and then offer my geometrical solution: the Mean Term of Distributive Justice, according to my calculations, is the Golden Ratio between the three Opposite Criteria of Distribution: Freedom, Wealth and Virtue (Figure 1. Aristotle's diagram showing the Mean Term of Distributive Justice: The Golden Ratio).

In the second part of the article (Section 3), I refer to the Doctrine of the Four Causes to show how Aristotle considers that the three Criteria of Distribution and their Mean Proportional (Freedom, Wealth, Virtue and Golden Ratio) represent, in fact, the First Principles of Political Justice. In accordance with his Dialectical Method, I explain that in the Politics Aristotle speaks of Freedom as the Efficient Cause, Wealth as the Material Cause, Virtue as the Final Cause, and Golden Ratio as the Formal Cause of Political Justice.

In the third part of the article (Section 4), I refer to the Final Cause of Political Justice to show how Aristotle establishes a clear difference between the Absolute Best Constitution (the Aristocratic Politeia) whose Final Cause is the Happy and Self-Sufficient Life in accordance with Virtue, and the Best Constitution in certain circumstances (the Politeia) whose Final Cause is Prosperity. Indeed, the goal of the Absolute Best Constitution is none other than to achieve Peace and Harmony between the different social classes (Democrats, Oligarchs and Aristocrats). Consistently with this principle, it is shown that, applying the Golden Triangle (the Formal Cause of Political Justice) to the different constitutions, the Best Form of Government is the Aristocratic Politeia, i.e., a mixture of Democracy, 
Oligarchy and Aristocracy, as Aristotle states in his Politics (Figure 2. Aristotle's Diagram showing the Best Form of Government: The Aristocratic Politeia.).

\section{ARISTOTLE'S DIAGRAM SHOWING THE MEAN TERM \\ OF DISTRIBUTIVE JUSTICE: THE GOLDEN RATIO}

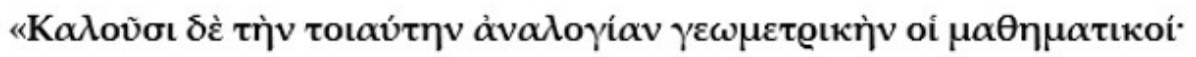

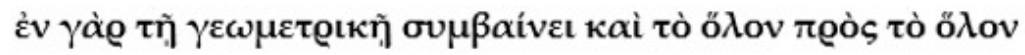

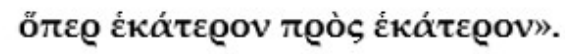

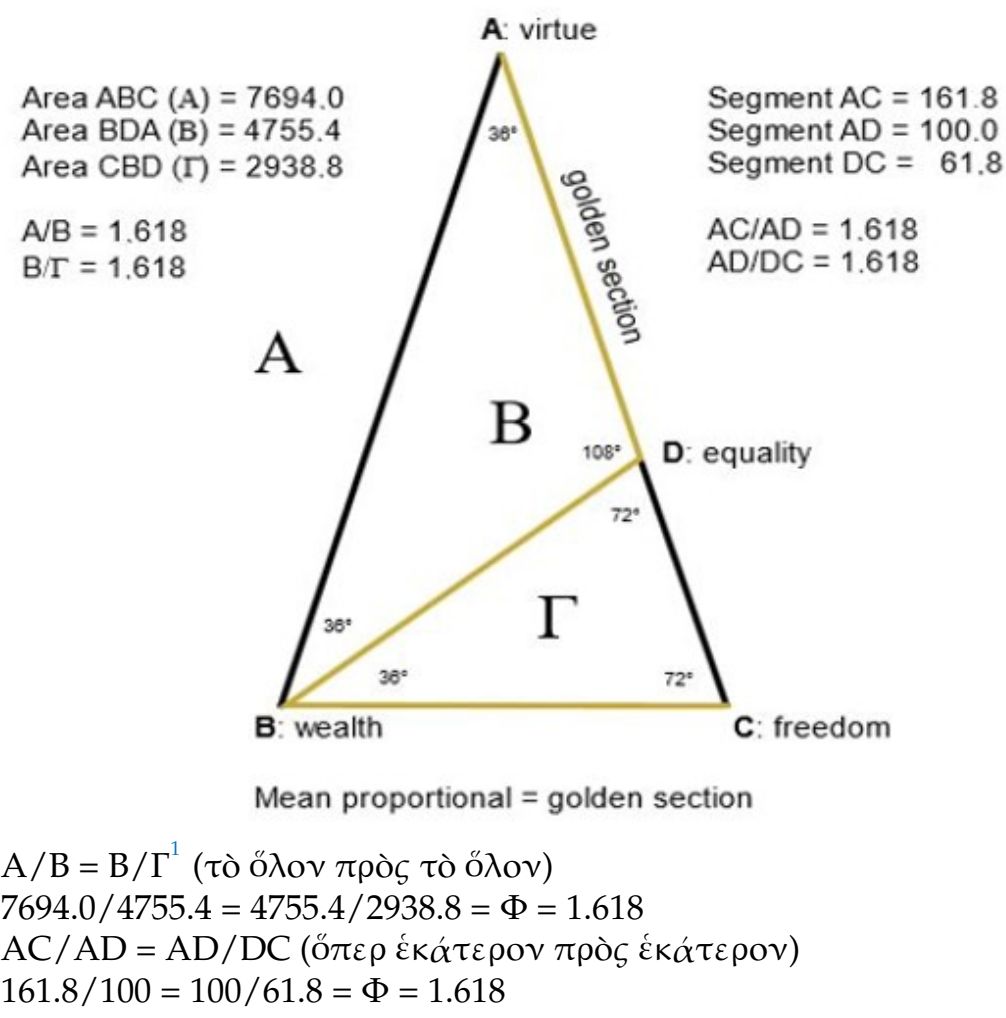

Figure 1. The Mean Term of Aristotle's Distributive Justice is the Golden Ratio between the Three opposing Criteria of Distribution: Freedom, Wealth and Virtue. 


\section{ARISTOTLE'S DIAGRAM SHOWING THE BEST FORM OF GOVERNMENT: THE ARISTOCRATIC POLITEIA}

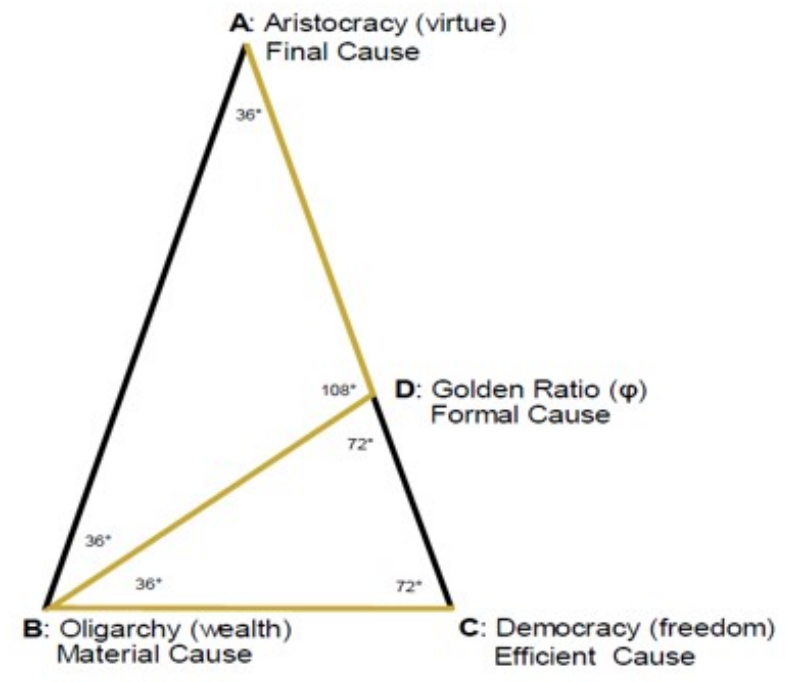

Figure 2. The Best Form of Government is the Golden Ratio between the Three opposing Constitutions: Democracy, Oligarchy and Aristocracy. The Aristocratic Politeia.

\section{In Search of the Mean Term of Distributive Justice}

Not so long ago, A. Sen highlighted the inherent problem in the attempt to choose a single criterion of Distributive Justice of political and economic rights and duties among citizens: at the heart of the particular problem of a unique impartial resolution of the perfectly just society is the possible sustainability of plural and competing reasons for justice, all of which have claims to impartiality and which nevertheless differ from-and rival-each other. A. Sen [9] illustrates the problem with an example in which we have to decide which of three children-Anne, Bob and Carla-should receive a flute over which they are quarrelling. Theorists of different persuasions, such as the utilitarians, or the economic egalitarians, or the libertarians, take the view that there is a simple and fair resolution to consider, and there is no difficulty in identifying it. The point is that it is not easy to brush aside as foundationless any of the claims based respectively on the pursuit of human fulfilment, or removal of poverty, or entitlement to enjoy the products of one's own labor. The different resolutions all have serious arguments in support of them, and we may not be able to identify, without some arbitrariness, any of the alternative arguments as being the one that must invariably prevail [10].

More than two thousand years ago, Aristotle used the same example to address the same issue and argue that since people do not agree on how to properly distribute political and economic rights and duties among citizens (since democrats believe that the best criterion of Distributive Justice is the status of a freeman while the supporters of Oligarchy identify it as wealth or nobility of birth, and the supporters of Aristocracy as excellence of character), the Distribution of political rights will be fair if it is done according to a certain Proportion. In fact, Aristotle comments that although there is a consensus among the people that justice in distribution must be according to merit ( $\dot{\alpha} \xi \dot{q} \alpha v)$ in some sense, at the same time, however, he documents a widespread and profound disagreement about which merit should be the fairest measure of value. Indeed, the unique value that democrats cherish is freedom $(\dot{\varepsilon} \lambda \varepsilon v \theta \varepsilon \rho \dot{c} \alpha)$ and, consequently, wealth and honor should be distributed proportionally among all free and equal citizens (excluding slaves, foreign serfs or resident aliens); for oligarchs, the unique value is wealth $(\chi \rho \eta \mu \alpha \tau \alpha)$ : in this case, the distribution of 
political and economic rights and duties among citizens is calculated according to their level of income and property; while for the aristocrats, the unique value is virtue ( $\dot{\alpha} \rho \varepsilon \tau \eta \dot{)}$ and, consequently, the distribution must be proportional to the goodness and political virtue of its citizens. Therefore-Aristotle asks us-supposing all were in one city, that is, the good and the wealthy and noble and also an additional mass of citizens, will there be a dispute, or will there not, as to who ought to govern? Aristotle's answer is obviously affirmative, and consequently he puts the terms of the political question as follows:

«All are agreed that justice in distributions must be based on desert of some sort, although they do not all mean the same sort of desert; democrats make the criterion free birth; those of oligarchical sympathies wealth, or in other cases birth; upholders of aristocracy make it virtue. Justice is therefore a sort of proportion» [2] (Book V, 3).

\subsection{Theorem: The Theory of the Mean Is Necessary to Find the Mean Term of Distributive Justice}

As we know, in Book II of the Nicomachean Ethics Aristotle distinguishes between the Arithmetic Mean relating to virtue ( $\mu \varepsilon \dot{\sigma o} v)$, which is equidistant between the extremes, and the Geometric Mean relating to us $(\mu \varepsilon \sigma o ́ \tau \eta \zeta)^{2}$, which differs from person to person:

«Now of everything that is continuous and divisible, it is possible to take the larger part, or the smaller part, or an equal part, and these parts may be larger, smaller, and equal either whit respect to the thing itself or relatively to us; the equal part being a mean between excess and deficiency» [2] (Book II, 1106a 25-29).

In agreement with H. H. Joachim ${ }^{3}$ and W. F. R. Hardie ${ }^{4}$, the first important thing to note about this mathematical distinction between the Mean Term according to the Arithmetical Proportion and the Mean Term according to the Geometrical Proportion, is that Aristotle refers to the Material Cause of Ethical Virtue (Passions and Actions) as a quantity that is also continuous ( $\sigma \cup \vee \varepsilon \chi \eta \dot{\eta})$, i.e., divisible ad infinitum. Certainly, this important clarification allows us to better understand Aristotle's Definition of Ethical Virtue as a Geometric Mean relative to us, since in order to calculate it, we must inevitably refer to a Mean Term according to the Geometrical Proportion that is also Continuous, i.e., divisible ad infinitum. In fact, Ethical Virtue concerns Passions and Actions, and in these there is excess, defect and intermediate. So, the question is: how do we choose Ethical Virtue? Aristotle's answer is that Ethical Virtue is a characteristic of our character referring to our capacity for choice and that it consists in a Mean Proportional relative to us ( $\mu \varepsilon \sigma o ́ \tau \eta \zeta$ ) determined by a Rational Principle, the Rational Principle by which the man of Practical Wisdom would determine it (EN, II, 1106b35-1107a2). Indeed, the point is that the Geometric Mean is not one, nor the same for all since, in order to get it, several variables that are individual and circumstantial must be calculated. Aristotle illustrates this question with an example from the training of athletes. If a ten-euro ration (of meat) is too much and two euros too little, the coach cannot necessarily order six euros. This might be too much for the beginner, but too little for Milo of Crotona, who won the wrestling championship in six Olympic Games and in seven Pythian Games (EN, II, 1106a 31-b5). Thus, a master of any art chooses the Mean Term not in virtue but relatively to us according to the Rational Principle of Practical Wisdom.

However, in accordance with Hardie: «A man is not called brave because he kills neither too many nor too few of the enemy. A man does not avoid the extremes of buffoonery and boorishness by making neither too many jokes nor too few. The second point is that all virtuous action, including those in which external divisible objects are involved, can be right or wrong in respects which are not quantitative at all. They must be done, for example, at the right times, with reference to the right objects, towards the right people. Aristotle makes this statement in the very center of his exposition of the doctrine of the mean» [4] (p. 132). Perhaps, in relation to this fundamental aspect of the Doctrine of the Mean, what Aristotle is telling us is that in order to determine the Geometric Mean relative to us, we must measure several variables that are not only quantitative and 
divisible ad infinitum - such as the Passions (different degrees of pleasure or pain that we can experience in love, hate, joy, desire, anger, friendship, fear, pity, confidence, longing, jealousy, etc.) and the Actions (different amounts of goods that we can possess, such as food, drink, health, wealth, honor, public offices, wisdom etc.)-but also qualitative as they relate to the remaining First Principles of Virtue: Efficient Cause, Final Cause and Formal Cause.

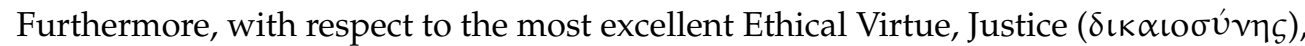
as we know, Aristotle distinguishes two kinds of Particular Justice (EN V, 5, 1130 b 30-1131 a9): Justice in the Distribution of divisible public goods, such as honor, wealth and the other divisible assets of the community, which may be allotted among its members in equal

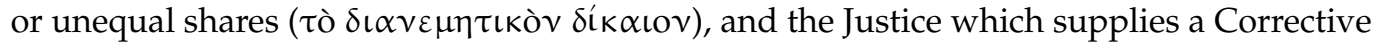
Principle in private transactions ( $\tau o ̀ ~ \delta\llcorner\circ \theta \omega \tau \iota k o ́ v ~ \delta i ́ k \alpha \iota v)$ ). Now, regarding Distributive Justice, Aristotle tells us that it is a kind of Mean Term, but not in the same way as the other virtues, for in this case the Geometric Mean $(\mu \varepsilon \sigma o ́ \tau \eta \zeta)$ is relative to a Proportional Equality

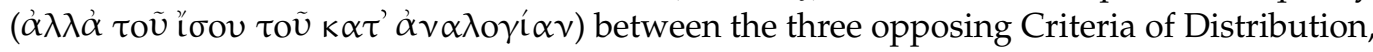
whereas in any other virtue the Geometric Mean is relative to us and lies between two extremes (excess and deficiency):

«Justice is a mode of observing the mean, though not in the same way as the other virtues are, but because it is related to a mean, while Injustice is related to the extremes. Also, Justice is that quality in virtue of which a man is said to be disposed to do by deliberate choice that which is just, and, when distributing things between himself and another, or between two others, not to give too much to himself and too little to his neighbor of what is desirable, and too little to himself and too much to his neighbor of what is harmful, but to each what is proportionately equal; and similarly, when he is distributing between two other persons» [2] (Book V, 5, 1134a1-18).

Thus, in order to determine the Geometric Mean of Distributive Justice, Aristotle himself shows us very clearly the way to follow, the method of investigation, which is mathematical since it implies the construction of a certain Geometric Figure $(\delta \iota \alpha \dot{\gamma} \gamma \rho \alpha \mu \mu \alpha)$ that visually represents it:

«For when deliberating one seems in the procedure described to be pursuing an investigation or analysis that resembles the analysis of a figure in geometryindeed it appears that though not all investigation is deliberation, for example, mathematical investigation is not, yet all deliberation is investigation-and the last step in the analysis seems to be the first step in the execution of the design» [2] (Book III, 1112b 20-24).

This mathematical approach to the problem of Deliberation of the Geometric Mean is well commented on by W. D. Ross, who explains that Aristotle has in mind the method of discovering the solution to a geometrical problem ${ }^{5}$. So, the geometrical problem to be solved by constructing the $\delta \iota \alpha \dot{\gamma} \gamma \rho \alpha \mu \mu \alpha$ required by Aristotle is the following:

"All are agreed that justice in distributions must be based on desert of some sort, although they do not all mean the same sort of desert; democrats make the criterion free birth; those of oligarchical sympathies wealth, or in other cases birth; upholders of aristocracy make it virtue. Justice is therefore a sort of proportion; for proportion is not a specific characteristic of the monadic number ${ }^{6}$, but of the number as a whole. For proportion is equality of ratios and involves four terms at least. That discrete proportion involves four terms is plain, but so too does continuous proportion, for it uses one term as two and mentions it twice; e.g., as the line $A$ is to the line $B$, so is the line $B$ to the line $\Gamma$; the line $B$, then, has be mentioned twice, so that if the line $B$ be assumed twice, the proportional terms will be four. And the just, too, involves at least four terms, and the ratio is the same because it joins the terms in the same way ${ }^{7}$. As the term $A$, then, is to $B$, so 
will $\Gamma$ be to $\Delta$, and therefore, alternando, as $\mathrm{A}$ is to $\Gamma$, B will be to $\Delta$. Therefore, also the whole is in the same ratio to the whole. If the division joins the terms in this way, then it joins rightly. In fact, the conjunction between the lines $\mathrm{A} \Gamma$ and $\mathrm{B} \Delta$ is what is just in distribution, and this species of the just is a mean proportional, and the unjust is what violates the proportion; in fact, this mean proportional is the just proportion. Mathematicians call this kind of proportion geometrical; for it is in geometrical proportion that it follows that the whole is to the whole as either part is to the corresponding part. But this proportion is not continuous: for it does not arise from a single dimension ad infinitum ${ }^{8}$. This, then, is what the just is-the proportional; the unjust is what violates the proportion».

To put it another way:

- The Mean Term of Distributive Justice is relative to a Proportional Equality between the three opposing Criteria of Distribution-Freedom, Wealth, and Virtue-, and unjust distribution is that which violates this Proportional Equality. The corresponding justice and injustice are a special Ethical Virtue and Vice: the ethical motive of just action is the $\pi \lambda \varepsilon$ ov $\varepsilon^{\xi} \dot{i} \alpha$, covetousness or love for gain, the desire to secure more than the agent's share of honor, wealth or bodily safety. The rights and the wrongs in this case are always rights of one individual against another, wrong done by one private individual to another. So, the Geometric Mean of Distributive Justice is relative to a Proportion which is composed of Four terms (i.e., the Three Criteria of Distribution and their Mean Proportional): A/B = C/D.

- Moreover, this Proportion is not discrete but Continuous, i.e., divisible ad infinitum. Aristotle explains that Proportion is equivalent to analogia, equality of ratios, i.e., $\mathrm{A} / \mathrm{B}=\mathrm{C} / \mathrm{D}$ if the proportion is Discrete, and $\mathrm{A} / \mathrm{B}=\mathrm{B} / \mathrm{C}$ if is Continuous; "and the just too involves at least four terms, and the ratio is the same because it joins the terms in the same way. As the term $A$, then, is to $B$, so will $C$ be to $D$, and therefore, alternando, as A is to C, B will be to D. Therefore, also the whole is in the same ratio to the whole. If the division joins the terms in this way, then it joins rightly». That is, the Geometric Mean is relative to a Proportion that is also Continuous because it joins the terms so that the ratio between the whole and its parts is the same: $A / C=B / D$.

- However, this Proportion is Continuous, i.e., divisible ad infinitum, in several dimensions and not only in one, which means that we do not have to draw a one-dimensional Geometric Figure (i.e., the Line that possesses only the dimension of length). In fact, since we have to calculate the Geometric Mean relative to a Proportional Equality between the three opposing Criteria of Distribution, we have to construct a Triangle $\mathrm{ABC}$, which, in effect, is a two-dimensional (length and width) Geometric Figure.

- Thus, in the Triangle ABC, the Point of Conjunction or Intersection between line AC and line $\mathrm{BD}$ determines what is just in the distribution: «In fact, the conjunction between the lines $\mathrm{AC}$ and $\mathrm{BD}$ is what is just in distribution, and this species of the just is a mean proportional, and the unjust is what violates the proportion; in fact, this mean proportional is the just proportion». In other words, the Mean Term of Distributive Justice is determined by the point of conjunction between lines AC and $\mathrm{BD}$ of a triangle ABC.

- Finally, Aristotle gives us the definition of the Rational Principle that underlies the Geometrical Proportion that we need to identify in order to be able to construct the Geometric Figure or $\delta \iota \alpha ́ \gamma \rho \alpha \mu \mu \alpha$ required by Aristotle, knowing that the 'last step in the analysis seems to be the first step in the execution of the design': "Mathematicians call this kind of proportion geometrical; for it is in geometrical proportion that it follows that the whole is to the whole as either part is to the corresponding part».

2.2. Proof of the Theorem: The Mean Term of Distributive Justice Is the Golden Ratio between the Three Opposite Criteria of Distribution

R. A. Gauthier and J. Y. Jolif, as well as H. Rackham, W. D. Ross, W. F. R. Hardie and most modern scholars, have translated and interpreted Aristotle's words as if the great 
philosopher were referring almost academically to the two properties of proportion, namely, the Componendo property: if $A / B=C / D$, then $(A+B) / B=(C+D) / D$, and the Alternando property: if $A / B=C / D$, then $(A+C) /(B+D)=A / B$. This interpretation has never been questioned much, especially by mathematicians. But for us philosophers-especially those like H. H. Joachim - this interpretation does not lead us to the knowledge of the Mean Term of Distributive Justice. The most popular interpretation of Aristotle's geometric theorem, in fact, does not solve the problem: what is the Geometric Figure that should reveal to us the Mean Term of Distributive Justice that is relative to a certain Geometrical Proportion? What Geometrical Proportion is Aristotle talking about? It is not known. For some brilliant scholars, such as Hardie ${ }^{10}$ and Ross ${ }^{11}$, it is not a question of arriving at the knowledge of the Mean Term of Distributive Justice, because according to them, Aristotle only means that each political regime is based on a single distributive criterion, which is applied proportionally to the citizens (e.g., in an oligarchic regime, political and economic rights are distributed proportionally to wealth; in a democratic regime proportionally to the status of a freeman, and so on). In other words, most scholars have not even understood the terms of the political question posed by Aristotle, and indeed they also deny that there is a mathematical problem to be solved. On the contrary, I believe that the political question exists and that the knowledge of the best criterion of distributive justice can be obtained precisely through a geometric calculation that establishes the Mean Term between the three opposing criteria of distribution: freedom, wealth and virtue. Moreover, in accordance with Joachim's commentary ${ }^{12}$, the key point here is that Aristotle thought that to come to understand the best distributive criterion requires a high level of practical wisdom, a level possessed only by the legislative genius of the statesman.

Therefore, I will try to explain my geometrical and philosophical interpretation of the Aristotelian definition of the Mean Term of Distributive Justice, which refers, in my opinion, to the Division into Extreme and Mean Ratio or Golden Ratio $(\mathrm{AC} / \mathrm{AD}=\mathrm{AD} / \mathrm{DC}=\Phi)^{13}$; specifically, Aristotle's definition refers to the $\delta\left\llcorner\alpha \dot{\gamma} \gamma \rho \alpha \mu \mu \alpha\right.$ of the Golden Triangle ${ }^{14}$. In fact, the Rational Principle at the basis of the Golden Ratio is Geometrical Equality, which is opposed to Arithmetical Equality, since it refers to Proportional Equality between the Whole (the Polis) and its Parts (Opposing Social Classes: Democrats, Oligarchs and Aristocrats); and this Distributive Principle corresponds exactly to the Aristotelian definition of Continuous Proportion that we are looking for. In effect, there is only one type of triangle that satisfies the conditions indicated by Aristotle, namely the one in which «the whole is to the whole as either part is to the corresponding part». This is the Golden Triangle, which is an isosceles triangle such that the ratio of the Whole (areas) to its Parts (segments) is equal to $\Phi^{15}$.

\section{Demonstration}

Let $A B C(A)$ be the given Golden Triangle with base angles of $72^{\circ}$ and a vertex angle of $36^{\circ}$. Now divide the base angle $A B C$ by a diagonal $B D$ that intersects $A C$ at $D$. Then consider the Smaller Triangle CBD $(\Gamma)$ : this triangle has the vertex angle $\mathrm{CBD}$ of $36^{\circ}$ and the angle $\mathrm{BCD}$ of $72^{\circ}$; then the angle $\mathrm{BDC}$ is also of $72^{\circ}$ in a way that the triangle is also Golden and as a result, $\mathrm{BC}=\mathrm{BD}$. But as the Larger Triangle BDA (B) has the base angles ABD and $\mathrm{BAD}$ of $36^{\circ}$ and the remaining one of $108^{\circ}$, then the triangle is also Golden and as a result, $\mathrm{BD}=\mathrm{AD}$. Thereby, the three sides $\mathrm{BC}, \mathrm{BD}$ and $\mathrm{AD}$ are equal in length. But as the Golden Triangles $\mathrm{ABC}(\mathrm{A})$ and $\mathrm{CBD}(\Gamma)$ are similar because all their corresponding angles are equal, then all their sides are also proportional, $\mathrm{AC} / \mathrm{BD}=\mathrm{BC} / \mathrm{DC}$. Consequently, the ratio of the longest side to the shortest side of these two triangles is the same. But since we have the hypothesis that $\mathrm{BC}=\mathrm{BD}=\mathrm{AD}$, by substituting the terms we finally obtain the Continuous Proportion, i.e., divisible ad infinitum, that Aristotle would want us to find, and which is called Division in Extreme and Mean Ratio or Golden Ratio: AC/AD = AD/DC. Therefore, «if the division joins the terms in this way, then it joins rightly. In fact, the conjunction between the lines AC and BD is what is just in distribution, and this species of the just is a mean proportional, and the unjust is what violates the proportion; in fact, this mean 
proportional is the just proportion». Indeed, the diagonal BD cuts the line AC in Extreme and Mean Ratio, with $\mathrm{AD}(\mathrm{AD}=\mathrm{BC}=\mathrm{BD})$ being the Mean Ratio or Golden Ratio (or Golden Section), and DC the Extreme Ratio. Thus, it is shown that the Mean Term of Distributive Justice is the Golden Ratio AD, which is determined by the diagonal BD dividing the line AC at the point of conjunction D, as Aristotle had indicated. Finally, we can now understand Aristotle's definition of the Golden Ratio: «Mathematicians call this kind of proportion geometrical; for it is in geometrical proportion that it follows that the whole is to the whole as either part is to the corresponding part». In fact, the Golden Triangle is an isosceles triangle such that the ratio of the longest side or the hypotenuse (AC) to the shortest side or to the base (BC) is equal to $\Phi$; and such that the ratio of the area of the largest triangle (B) to the smallest $(\Gamma)$ is equal to $\Phi$.

To clear the field once and for all from the interpretation that has been given so far of the Geometrical Theorem, it is sufficient to add that Aristotle made very clear the idea that the geometrical concept of Whole (ö $\lambda$ ov) does not coincide with the arithmetical concept of Sum (Componendo property), i.e., that the whole is more than the sum of its parts: "In all things which have a plurality of parts, and which are not a total aggregate but a whole of some sort distinct from the parts, there is some cause; in as much as even in bodies sometimes contact is the cause of their unity, and sometimes viscosity or some other such quality» ${ }^{16}$. Furthermore, Aristotle applied the general principle of Holism to his Cosmology to explain the First Principle of the Universe, that is, the Unity of Opposite Elements: "Some people, however, have wondered how the cosmos, if it is composed of the "opposite" principles (I mean dry and wet, cold and hot), has not long ago been destroyed and perished; it is as if men should wonder how a city survives, composed as it is of the most opposite classes (I mean poor and rich, young and old, weak and strong, bad and good). They do not recognize that the most wonderful thing of all about the harmonious working of a city-community is this: that out of plurality and diversity it achieves a homogeneous unity capable of admitting every variation of nature and degree. But perhaps nature actually has a liking for opposites; perhaps it is from them that she creates harmony, and not from similar things, in just the same way as she has joined the male to the female, and not each of them to another of the same sex, thus making the first harmonious community not of similar but of opposite things». And the cause of the Unity of Opposite Elements is precisely Proportional Equality: «The cause of its preservation is the agreement of the elements, and the cause of the agreement is the principle of equal shares and the fact that no one of them has more power than each of the others: for the heavy is in equipoise with the light, and the hot with its opposite. In these greater matters nature teaches us that equality is the preserver of concord, and concord is the preserver of the cosmos, which is the parent of all things and the most beautiful of all» [17].

\section{Discussion: How to Know the First Principles of Political Justice through the Dialectical Method}

As we have seen, in Book V of the Nicomachean Ethics, Aristotle arrives at the knowledge of the First Principles ${ }^{17}$ of Political Justice using the Dialectical Method in line with what was stated at the beginning of the Ethics. That is, Aristotle uses inductive arguments, starting from the evidence that there are three opposing views on what should be the right criterion for distributing public goods among citizens, and showing how all these different views contribute to the truth. Indeed, the First Principles of Political Justice cannot be proved, because they are the first truths in the sphere of political conduct, and therefore there are no prior truths from which they can be deduced. But the First Principles can be established dialectically from a critical analysis of the values underlying the various political Constitutions, values that are then correlated and ordered hierarchically-thanks to Mathematics - in a whole Geometric Figure or $\delta$ í $\gamma \rho \alpha \mu \mu \alpha$. Moreover, in the same Book, Aristotle revels the Formal Cause of Distributive Justice, that is, the Golden Ratio, which harmoniously blends the three opposing Criteria into a unitary whole, so that none of them is more powerful than the others; thus, freedom is in balance with wealth, wealth with 
virtue and virtue with freedom. Finally, in the Politics, Aristotle explains the other First Principles of Political Justice: Books III, IV, VII and VIII: Final Cause; Books VII and VIII: Efficient and Material Cause:

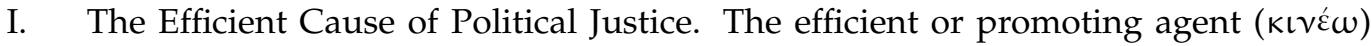
of the Just Distribution is love of Freedom, which means that only freemen can prudently choose the Rational Principle underlying the Golden Ratio, i.e., Geometrical Equality. Freemen like the Greeks, whose character blends courage and intelligence, i.e., capacities for self-government and for empire, while the people of «other nations inhabiting the cold places and those of Europe are full of spirit but somewhat deficient in intelligence and skill, so that they continue comparatively free, but lacking in political organization and capacity to rule their neighbors. The peoples of Asia on the other hand are intelligent and skillful in temperament, but lack spirit, so that they are in continuous subjection and slavery. But the Greek race participates in both characters, just as it occupies the middle position geographically, for it is both spirited and intelligent; hence it continues to be free and to have very good political institutions, and to be capable of ruling all mankind if it attains constitutional unity. The same diversity also exists among the Greek races compared with one another: some have a one-sided nature; others are happily blended in regard to both these capacities. It is clear therefore that people that are to be easily guided to virtue by the lawgiver must be both intellectual and spirited in their nature (... ). Moreover, it is from this faculty that power to command and love of freedom are in all cases derived; for spirit is a commanding and indomitable element» [19]. Thus, Aristotle architecturally designs the internal structure of the Best Constitution (its social and political institutions) by applying the Distributive Principle of Geometrical Equality: citizens are divided into six classes with different functions, since it is necessary for the self-sufficient State to have the classes of (1) husbandmen (slaves or foreign servants), (2) artisans, (3) war-like class, (4) a well-to-do class, (5) priests and (6) judges of what is just and expedient. Having said this, the citizens who are to perform the constitutional functions must be absolutely free, i.e., they should not lead a mechanical or mercantile life (because such a life is ignoble and contrary to virtue), nor should they be cultivators of the land (for leisure is needed both for the development of virtue and for active participation in politics); that is why Aristotle (Politics VII, 8) limits the Citizenship to two classes-war-like class and judges-which will exercise power in turn according to their age and their virtues: courage, and theoretical and practical wisdom.

II. The Material Cause of Political Justice. The material element ( tion is Wealth. In the Nicomachean Ethics Aristotle refers primarily to property rights, using property to cover possessions, honor and bodily security, i.e., all those things to which an individual citizen may be entitled to the exclusion of all other citizens. In agreement with Joachim's commentary, there is no doubt that Aristotle may be thinking partly of distributions of surplus revenue (e.g., from the silver mines), or of windfalls of public money (e.g., of gifts of corn from foreign potentates, or goods escheated of the State) [6] (p. 139-140). However, in the Politics and with reference to the Best Constitution, Aristotle opposes the Platonic idea that land ownerships should be common to all citizens, stating on the contrary that it should belong to those who possess arms and share political rights-i.e., war-like class and judges-, and that only the use of part of it should be in common to all in a spirit of friendship, so that no citizen should lack food: «It has been stated before that the land ought to be owned by those who possess arms and those who share the rights of the constitution, and why the cultivators ought to be a different caste from these, and what is the proper extent and conformation of the country. We have now to discuss first the allotment of the land, and the proper class and character of its cultivators; since we advocate not common ownership of land, as some have done, but community in it brought about in a friendly way by the use of it, and we hold that no citizen should be ill supplied 
with means of subsistence» [19] (Book VII, 9, 1329b 36-1330a 10). Consequently and applying the Distributive Principle of Geometrical Equality, Aristotle states that it is necessary to divide the land of the better State into two parts, of which one part shall be for common use and the other for private use. And each of these two parts shall again be divided into two: of the common lands, one part shall be used for religious functions, and the other for common meals; of the private lands, one part shall be situated in the district near the frontiers, and the other in the district near the city; after which, two lots of land shall be allotted to each citizen, so that each shall have a part of land in both districts. In this way and with this fair distribution of wealth, according to Aristotle, the demands of equality and justice would be fulfilled.

III. The Final Cause of Political Justice. The end ( $\tau \dot{\varepsilon} \lambda$ o $)$, or the goal of the Just Distribution, is Virtue, which indicates that its purpose is not only the prevention of mutual crime or economic exchange but above all the Happy and Self-Sufficient Life in accordance with Virtue. Indeed, Aristotle explains that the difference between the Absolute Best Constitution and the Best Constitution in certain Circumstances lies in virtue, since Happiness is necessarily different from Prosperity. Actually: «The goal of the polis is the good life, and these things are means to that end. And a polis is an association of clans and villages in a perfect and self-sufficient existence, which in our view constitutes a happy and noble life. Therefore, the political communities must be considered to exist for the sake of good actions, and not for the sake of bare social life. Hence, those who contribute most to such an association have a greater share in the polis then those who are their equals or superiors in freedom or decent but not their equals in political virtue, or than those who surpass them in wealth but are surpassed by them in virtue» [19] (Book III, 9, 1281a 1-10). In fact, Aristotle explains that men have the same end both collectively and individually, and this end is Peace and Leisure, which are essential because peace is the end of war, while leisure is the end of business. Indeed, «courage and fortitude are necessary for business, love of wisdom for leisure, temperance and justice for both times, and more especially when men are at peace and have leisure» [19] (Book VII, 15, 1334a 24-26). Therefore, men should prefer to carry out theoretical and practical activity of the soul, trying to accumulate as many virtues as possible both intellectual and ethical, rather than preferring the accumulation of wealth, and external goods. In fact, accumulating great wealth cannot be the goal of the happy life, although most people today think it is. That is why Aristotle devotes the last Book of Politics to the Education of the Young, which in the Absolute Best Constitution must be public, unique and equal for all citizens.

IV. The Formal Cause of Political Justice. The form ( $\mu \circ \rho \varphi \eta$ ), or the geometric figure of the Just Distribution, is determined by the Rational Principle underlying the Mean Term of Distributive Justice, that is, as we have seen, the Golden Ratio $(\Phi)$. And the Rational Principle underlying the Golden Ratio is Geometrical Equality, which is opposed to Arithmetical Equality, since it achieves the Unity or Harmony of Opposite Elements of the Polis, namely the Democratic, Oligarchic and Aristocratic classes. In fact, Geometrical Equality preserves harmony among citizens by preventing them from falling into the vice of $\pi \lambda \varepsilon$ ov $\varepsilon \xi \hat{i} \alpha$, greed or love of gain. Thus, the geometrical figure required by Aristotle, the Golden Triangle, indicates that the Geometric Mean of Aristotle's Distributive Justice is relative to a Proportional Equality (the Golden Ratio) between the three opposing Criteria of distribution, so that none of them is more powerful than the others; therefore, Freedom is balanced by Wealth, Wealth by Virtue, and Virtue by Freedom. Moreover, the Aristotelian $\delta \iota \alpha ́ \gamma \rho \alpha \mu \mu \alpha$ also allows us to highlight Aristotle's preferred criterion of distribution, ordering the three in a hierarchical manner. In fact, if the aim of the Absolute Best Constitution is the Happy and Self-Sufficient Life in accordance with Virtue, the first criterion of distribution to be considered must necessarily be Virtue (this is why I have placed Virtue at the apex of the Triangle). In this way the Aristotelian ideal would be realized, according 
to which those who are superior in political Virtue should deserve a greater share of economic and political rights than those who are equal or superior in Wealth or Freedom. From a purely mathematical point of view, finally, it is confirmed that in the bi-dimensional geometric figure of the Golden Triangle the Proportion is Continuous, i.e., divisible ad infinitum, as Aristotle had said; in fact, in the Golden Triangle the process of division can be repeated ad infinitum since, by sectioning the longest side with the shortest side, infinite isosceles triangles are formed that replicate the Golden Ratio. The rule in fact is that: "Golden triangles and gnomons can be sectioned into smaller triangles that are golden gnomons and triangles» [15] (p. 79). Additionally, in my opinion, Plato had already referred to the Golden Ratio, or Divine Proportion, when explaining his preference for Geometrical Equality over Arithmetical Equality. For Plato, Geometrical Equality is the best form of Equality because it refers to a 'Small Measure' that comes from the 'Judgment of Zeus'. And this Divine Measure, though small, always produces good things when applied to Political Justice:

«For there are two kinds of equality which, though identical in name, are often almost opposites in their practical results. The one of these any State or lawgiver is competent to apply in the assignment of honors-namely, the equality determined by measure, weight and number-by simply employing the lot to give even results in the distributions; but the truest and best form of equality is not an easy thing for everyone to discern. It is the judgment of Zeus, and men it never assists save in small measure, but in so far as it does assist either States or individuals, it produces all things good; for it dispenses more to the greater and less to the smaller, giving due measure to each according to nature; and with regard to honors also, by granting the greater to those that are greater in goodness, and the less to those of the opposite character in respect of goodness and education, it assigns in proportion what is fitting to each» $[20,21]$.

\section{Conclusions: If Happiness Is Necessarily Different from Prosperity, the Best Constitution Will Be the Aristocratic Politeia}

In Book I of the Nicomachean Ethics, Aristotle states that Happiness ( $\varepsilon \dot{v} \delta \alpha \iota \mu \mathrm{ov} \alpha$ ) is the end of the best life, although people do not have the same opinion about happiness. Continuously adopting the Dialectical Method, that is, collecting empirical and quantitative data, he explains that people tend to identify happiness with goods they do not possess: pleasure, riches, honor, wealth, wisdom etc. But Aristotle reduces the current visions of the happy life to three: the Life of Pleasure (Hedonistic Life) according to the astronomer and mathematician Eudoxus of Cnidos, who explains that all creatures, both rational and irrational, pursue the supreme good of pleasure over pain (Goods of the Body); the Life of the Public Man (Active Life), like Pericles, who tries to develop political activity with justice, serving the interests of the people, and thus obtaining social recognition, fame and wealth (External Goods); and the Life of the Thinker (Contemplative Life), like Plato and Aristotle himself, who considers that the supreme good consists in the activity of the soul according to the intellectual and ethical virtues, a necessary condition for enjoying theoretical and practical wisdom (Goods of the Soul). In 1096a 5 sqq., Aristotle dismisses the Life of Businessmen insofar as it is directed simply and solely to the acquisition of money, on the grounds that wealth is not an end, but a means to an end other than itself. Furthermore, in the Book VII of the Politics, Aristotle explains that no one will dispute that division of goods according to which they are of three kinds: the External, those of the Body and those of the Soul, and all of them must be possessed by happy person; however, he argues that the goods of the soul are the most important, and therefore, in the best form of government, citizens should strive to follow a virtuous conduct. That is why he opens Book VII of the Politics by saying that we must know the Happy and Self-Sufficient Life in accordance with Virtue to identify the Absolute Best Constitution, since the aim of the Happy and Self-Sufficient Life in accordance with Virtue and the Absolute Best Constitution is the same, i.e., Peace and Leisure: 
«Let us then take it as agreed between us that to each man there falls just so large a measure of happiness as he achieves of virtue and wisdom or virtuous and wise action: in evidence of this we have the case of God, who is happy and blessed, but is so on account of no external goods, but on account of himself, and by being of a certain quality in his nature; since it is also for this reason that prosperity is necessarily different from happiness-for the cause of goods external to the soul is the spontaneous and fortune, but nobody is just or temperate as a result of or owing to the action of fortune. And connected is a truth requiring the same arguments to prove it, that it is also the best state, and the one that does well, that is happy» [19] Book VII, 1, 1323 b 20-30.

In fact, referring to the Spartan Politeia (Politics, Book VII, 15)—considered one of the best Greek constitutions for being a mixed Constitution-Aristotle points out its constitutional limitations by stating that most military states remain secure in war, but perish when they have won their empire; in times of peace, they lose their sharp temper, like iron. The lawgiver is to blame, because he has not educated them to know how to use their Leisure Time. And since it appears that men have the same end both collectively and individually, and since the same distinctive aim must necessarily belong both to the best man and to the best government, it is clear that the virtues relating to leisure are essential; since Peace is the end of War, Leisure of Business. But the virtues useful for leisure and for its employment are not only those that operate during leisure but also those that operate in business; for many of the necessary goods must be available to give us the opportunity of leisure. Accordingly, courage $\left(\alpha \vee \delta \rho i \alpha_{\zeta}\right)$ and fortitude $(\kappa \alpha \rho \tau \varepsilon \rho i \alpha \zeta)$ are needed for business, love of wisdom $(\varphi \iota \lambda \circ \sigma o \varphi \dot{i} \alpha \zeta)$ for leisure, temperance ( $\sigma \omega \varphi \rho \circ \sigma v ́ v \eta \zeta)$ and justice ( $\delta$ เ $\alpha \iota \sigma u ́ v \eta \zeta)$ for both seasons, and more especially when men are at peace and have leisure; for war compels men to be just and temperate, whereas the enjoyment of prosperity and peaceful leisure tend to make them insolent. Therefore, much justice and much temperance are needed by those who are considered to be very prosperous and who enjoy all things considered to be blessings (health and wealth); these will most need wisdom, temperance and justice, the more they are at leisure and have an abundance of such blessings. It is clear therefore why a State that is to be happy and righteous must share in these virtues; for if it is disgraceful to be unable to use our good things, it is still more disgraceful to be unable to use them in time of leisure, and although showing ourselves good men when engaged in business and war, in times of peace and leisure to seem no better than slaves.

So, in the first thirteen chapters of Book IV of the Politics, which concern both the Absolute Best Constitution and the Constitution which can be best in certain circumstances, Aristotle infers that the Absolute Best Constitution is the Aristocratic Politeia, that is, a Geometric Mean between Democracy, Oligarchy and Aristocracy; while the Constitution best suited to situations in which the middle class predominates, is a Geometric Mean between Oligarchy and Democracy. Indeed, and referring to Book V of the Nicomachean Ethics, Aristotle argues that there being three Criteria claiming an equal share in the Constitution, it is manifest that the blend of two of them-Freedom and Wealth/Democracy and Oligarchy—should be called Politeia ( $\pi$ o $\lambda \iota \tau \varepsilon i \alpha)$, while the blend of all-Freedom, Wealth and Virtue/Democracy, Oligarchy, and Aristocracy-must be called Aristocratic Politeia ( $\dot{\alpha} \rho \iota \tau \tau о \kappa \rho \alpha \tau \iota \kappa \dot{\alpha} \tau о \lambda \iota \tau \varepsilon i ́ \alpha)$. The difference between the Absolute Best Constitution and the Best Constitution in certain circumstances, lies in Virtue since it is clear that Happiness is necessarily different from Prosperity:

«In most states then the name of aristocracy is given to that form of constitutional government, for the combination aims only at the well-off and the poor, wealth and freedom (since in almost the largest number of states the rich seem to occupy the place of the gentry); but as there are three things that claim equal participation in the constitution, freedom, wealth and virtue (for the fourth, what is called nobility, accompanies the two latter-nobility means ancient wealth and virtue), it is manifest that the mixture of the two factors, the rich and the poor, ought to 
be termed $\pi$ o $\lambda \iota \tau \varepsilon i ́ \alpha$, while the mixture of the three factors deserves the name of aristocratic most of all the various forms of aristocracy beside the true and best form» [19] Book IV, 8, 1294 a 10-25.

Moreover, in Book $\mathrm{V}$ of the Politics, Aristotle repeats again the differences between the $\pi \mathrm{o} \lambda \iota \tau \varepsilon \tilde{\imath} \alpha \iota$ and the $\dot{\alpha} \rho \iota \sigma \tau о \kappa \rho \alpha \tau \iota \kappa \dot{\alpha} \varsigma \pi \mathrm{o} \lambda \iota \tau \varepsilon\llcorner\alpha \zeta$ when speaking of Revolutions, explaining that in the Aristocratic Politeia when the three elements (the democratic, the oligarchic and the aristocratic) are not well-blended, small reforms can lead to seditions, revolutions and civil wars; and the same happens in the Politeia when the two elements (the democratic and the oligarchic) are not well-combined:

«But the actual overthrow of both $\pi 0 \lambda \iota \tau \varepsilon \tilde{\imath} \alpha \iota$ and aristocracies is mostly due to a deviation from justice in the actual framework of the constitution. For what starts it in the case of a $\pi$ o $\lambda \iota \tau \varepsilon i ́$ is that it does not contain a good blend of democracy and oligarchy; and in the case of an aristocracy, it is the lack of a good blend of those two elements and of virtue, but chiefly of the two elements (I mean popular government and oligarchy), for both $\pi \mathrm{o} \lambda \iota \tau \varepsilon \tilde{\imath} \alpha$ í and most of the constitutions that are called aristocracies aim at blending these. For this is the point of distinction between aristocracies and what are called $\pi \mathrm{o} \lambda \iota \tau \varepsilon\llcorner\tilde{\omega} v$, and it is owing to this that some of them are less and others more stable. (... ) Small reforms lead to revolution. And aristocracies are most liable to undergo revolution unobserved, through gradual relaxation, just as it has been said in what has gone before about all forms of constitution in general, that even a small change may cause a revolution. For when they give up one of the details of the constitution, afterwards they also make another slightly bigger change more readily, until they alter the whole system» [19] Book V, 1307a 7-1307b 8.

Finally, I fully agree with Enrico Berti's arguments on the nature of Aristotle's Absolute Best Constitution; according to him, the political regime described in Books VII and VIII of the Politics is an Aristocratic Politeia ${ }^{18}$. In fact, and to conclude, if we apply the Aristotelian $\delta \iota \alpha ́ \gamma \rho \alpha \mu \mu \alpha$ to the corresponding political Constitutions-Democracy, Oligarchy and Aristocracy - we obtain a Golden Triangle in which the diagonal BD cuts the segment AC into Extreme and Mean Ratio; so that the Absolute Best Constitution is equal to the Golden Ratio between the three opposing Constitutions: The Aristocratic Politeia.

Funding: This research received no external funding.

Institutional Review Board Statement: Not applicable.

Informed Consent Statement: Not applicable.

Acknowledgments: I would like to sincerely thank the mathematician Marco Pavone, who helped me to explore the extraordinary characteristics and properties of the Golden Ratio, and my beloved father, Pasquale Salamone, for helping me to recognize the mathematical notion of continuity in the Aristotelian Greek text. Special thanks also to Francesco Ribaudo, for his patient work in constructing the Aristotelian Diagram. Finally, a grateful thanks to the reviewers who helped me to improve the article with their constructive suggestions.

Conflicts of Interest: The author declares no conflict of interest.

\section{Note}

Area $\mathrm{ABC}=100 \times 153.88 / 2=7694.0 ;$ Area $\mathrm{BDA}=161.8 \times 58.78 / 2=4755.4$; Area CBD = 61.8 $\times$ 95.11/2 = 2938.8.

[11], In agreement with Burnet, who explains that the Greek word $\mu \varepsilon \sigma o ́$ ๆ $\zeta$ does not mean “only or even primarily the arithmetical mean" but is "the oldest word for a proportion of any kind however determined", that is, also or even mainly the geometrical mean.

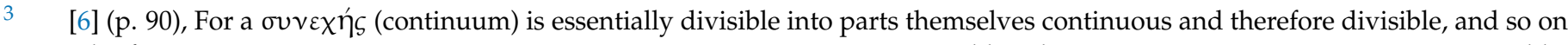
ad infinitum. A continuous quantum -e.g., an extensive continuous quantum like a line, or an intensive continuous quantum like a feeling - is such that it can always be divided into smaller parts or lesser degrees, but never into smallest parts or least degrees. 
Within any continuum you can always take a length or a degree exactly so long or intense as you require (the length or intensity being, of course, less than the whole).

4 [4] (p. 131), Quantity which is continuous is not merely divisible, but divisible ad infinitum: it has no indivisible, atomic, parts. This is the definition of continuous in De Caelo 268a6 and Physics 231b16. Thus, the sense conveyed by the whole phrase is that of 'continuous, i.e., divisible ad infinitum'.

5 [3] Note to $1112 \mathrm{~b} 21$ : Aristotle has in mind the method of discovering the solution of a geometrical problem. The problem being to construct a figure of a certain kind, we suppose it constructed and then analyze it to see if there is some figure by constructing which we can construct the required figure, and so on till we come to a figure which our existing knowledge enables us to construct.

6 [12], Book I, Definition 1: "A point is that which hath no part, or which hath no magnitude"). According to Pythagoras, the number one ( $\mu$ ov $\alpha \delta$ เ ко $\tilde{v} \dot{\alpha} \rho \imath \theta \mu \tilde{v})$ or the Pythagorean unitary point is indivisible, and this constitutes the first axiom of the mathematical sciences. What Aristotle probably means here is that no proportion can be constructed on the basis of a single term because the number one is indivisible. As we know, according to Euclid, at least three terms are needed to construct a proportion (continuous proportion).

7 [13], According to the Arabic version of the Nicomachean Ethics, the relative pronouns "oí $\varsigma \tau \varepsilon \kappa \alpha$ $\alpha$ " clearly refer to the terms of the Continuous proportion that Aristotle has just finished explaining: A/B=B/C. Unfortunately, these relative pronouns have been translated and interpreted as if they referred to the 'persons and things' Aristotle spoke of in the previous paragraph, when he introduced the Discrete proportion $A / B=C / D$. Nothing could be further from the interpretative truth.

8 This sentence of the geometric problem is the most difficult to translate and understand. It is probably the reason why scholars have made very serious mistakes in interpreting it and have not been able to solve the theorem. It is a double negative, and the meaning of the sentence should be as follows: "This proportion is continuous in several dimensions ad infinitum, and not only in one". Double negatives are perfectly correct in ancient Greek; and we can be sure that Aristotle, as the father of formal logic, knew how to use them very well.

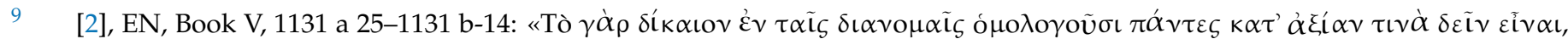

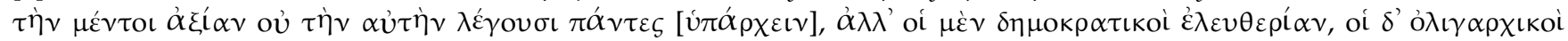

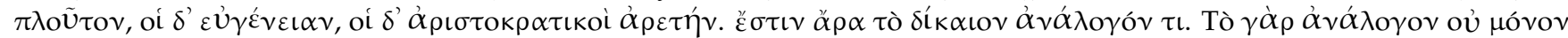

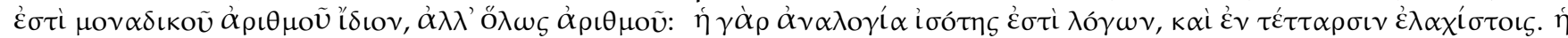

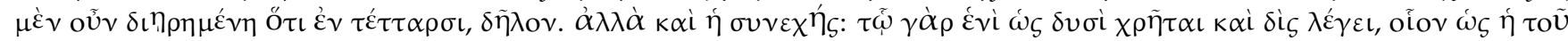

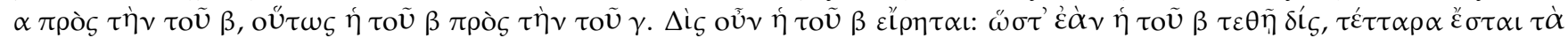

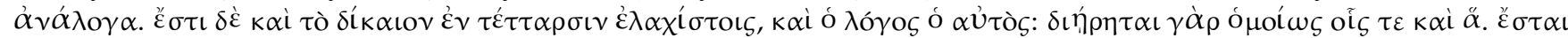

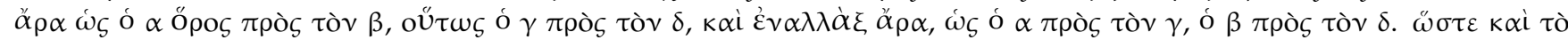

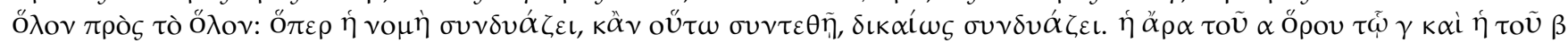

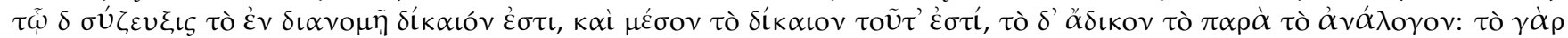

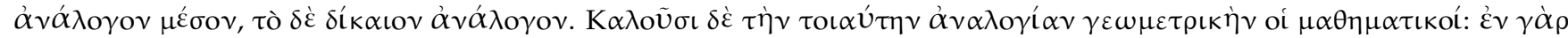

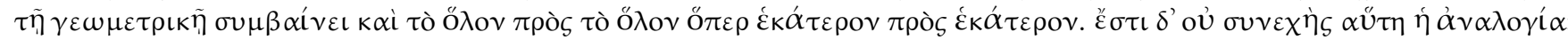

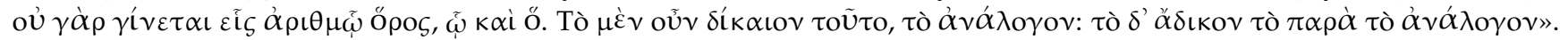

[4] (p. 189), There is no question here of arriving at a knowledge of the mean by a mathematical calculation, or quasi-calculation, which starts from a knowledge of extremes. The data required for pin-pointing the mean, the right size of the share to be assigned, are the relative merit of the recipients and the amount to be distributed.

11 [14], By distribution of honour, Aristotle means the distribution of office in accordance with the underlying hypotheses of the particular state that free status, wealth, noble birth, or virtue is to be the standard. This conception plays a large part in the Politics.

12 [6] (p. 138), Aristotle was thinking of the fundamental legislative acts by which privileges, powers and places were assigned to the constituent members or estates of the political community. But such distribution would require practical wisdom, which is an intellectual virtue, in its highest form, like the legislative genius of the architectural statesman.

[12], Book VI, Definition 3: A straight line is said to be cut into extreme and mean ratio, when the whole is to the greater segment, as the greater is to the lesser.

[12], (Book IV, Preposition 10): «To describe an isosceles triangle, having each of the angles at the base double of the third angle».

[15], The first definition of the Golden Ratio, in relation to areas, is given somewhat obliquely in Book II. A second, clearer definition, in relation to proportion, appears in Book VI. Euclid then uses the Golden Ratio, especially in the construction of the pentagon (in Book IV) and in the construction of the icosahedron and dodecahedron (in Book XIII).

[18], Aristotle describes two methods of inquiry that begin from our initial beliefs and the things we intuitively recognise, the 'things known to us', and claim to reach principles 'known by nature'. Empirical inquiry begins from perception, proceeds by induction and generalisation, and tests theories by appeal to experience. Dialectic inquiry begins from common beliefs, proceeds by raising and solving puzzles, and tests theories against common beliefs. Distinguishing these two methods is useful since they suggest two ways of passing the metaphysical realist test for genuine first principles. 
[22], «Finally, in Book Seven of the Politics, where Aristotle outlines the characteristics of the optimal constitution in the absolute sense (Aristocratic Politeia), pausing to illustrate the ideal number of citizens of which a city should be formed, the ideal region in which it should be located, the ideal qualities that the citizens should possess, and other such particulars, he returns to the problem of who is to exercise power, and observes that, as the citizens of such a city are of course all equal, government among equal persons can only be exercised in turn, so that all, first or second, command and all, first or second, obey. He even goes so far as to indicate when the citizens themselves must govern and when they must obey, and states that when young, having above all strength, they must obey, and in particular serve the city with arms, while when old, having above all wisdom, they must govern. The important thing is that all of them, being equal, should obey at one time of their lives, for example by waging war or doing business, and at another time rule. On the contrary, the important thing is to remember that, since the polis has as its end the good life, that is, happiness, instrumental activities, such as war and business, are means oriented towards activities that are ends in themselves, such as, respectively, peace and the good use of leisure time».

\section{References}

1. Gauthier, R.A.; Jolif, J.Y. Aristotle: L'Éthique, À Nicomaque; Vol. I, Introduction and Translation; Vol. II, Commentary; Nauwelaerts: Louvain, Belgium, 1959.

2. Rackham, H. Aristotle. In Nicomachean Ethics; Harvard University Press: Cambridge, MA, USA, 1934.

3. Ross, W.D. The Works of Aristotle Translated into English; Volume IX, Ethica Nicomachea; Oxford University Press: Oxford, UK, 1925.

4. Hardie, W.F.R. Aristotle's Ethical Theory; Oxford University Press: Oxford, UK, 1980.

5. Tricot, J. Aristote. In Étique à Nícomaque; Vrin: Paris, France, 1987.

6. Joachim, H.H. The Nicomachean Ethics. In A Commentary by the Late; Rees, D.A., Ed.; Clarendon Press: Oxford, UK, $1951 ;$ p. 141.

7. Salamone, M.A. The Aristotelian paradigm of distributive justice: The golden triangle. In Philosophy, Politics and Economics, Proceeding of the 23rd International Conference of Philosophy, Politics and Economics in the Global Era, Athens, Greece, 17-22 July 2011; Adam, M., Boudouris, K., Eds.; Iona Publications: Athens, Greece, 2014; pp. 207-221.

8. Salamone, M.A. Equality and Justice in Early Greek Cosmologies: The Paradigm of the Line of the Horizon. Philos. Cosmol. 2017, $18,22-31$.

9. Sen, A. The Idea of Justice; Harvard University Press: Cambridge, MA, USA, 2009.

10. Knoll, M.; Snyder, S.; Şimsek, N. New Perspectives on Distributive Justice: Deep Disagreements, Pluralism, and the Problem of Consensus; De Gruyter: Berlin, Germany; Boston, MA, USA, 2019.

11. Burnet, J. The Ethics of Aristotle; Metheuen: London, UK, 1900; p. 70.

12. Euclid-Heath, T. The Thirteen Books of Euclid's Elements, 2nd ed.; Heath, T., Ed.; Cambridge University Press: Cambridge, UK; New York, NY, USA; Dover, UK, 1956.

13. Fidora, A.; Akasoy, A. The Arabian Version of Nicomachean Ethics, 1st ed.; Brill: Leiden, The Netherlands, $2005 ;$ p. 32.

14. Ross, W.D. Aristotle; Routledge: London, UK; New York, NY, USA, 1995.

15. Livio, M. The Golden Ratio: The Story of PHI, the World's Most Astonishing Number; Broadway Books: New York, NY, USA, 2002.

16. Aristotle. Metaphysics, Volume I: Books 1-9; Tredennick, H., Ed.; Harvard University Press: Cambridge, MA, USA, 1933; Book VIII.

17. Aristotle. On the Cosmos; Forster, E.S., Furley, D.J., Eds.; Harvard University Press: Cambridge, MA, USA, 1955; Chapter V.

18. Irwin, T. Aristotle's First Principles; Oxford University Press: Oxford, UK, 1988.

19. Aristotle. Politics; Rackham, H., Ed.; Harvard University Press: Cambridge, MA, USA, 1932.

20. Plato. Laws, Volume I: Books 1-6; Bury, R.G., Ed.; Harvard University Press: Cambridge, MA, USA, 1926.

21. Salamone, M.A. The Two Supreme Principles of Plato's Cosmos-The One and the Indefinite Dyad-The Division of a Straight Line into Extreme and Mean Ratio, and Pingala's Mātrāmeru. Symmetry 2019, 11, 98. [CrossRef]

22. Berti, E. Aristotele e la democrazia. In Aristotele e la storia; Rossitto, C., Coppola, A., Biasutti, F., Eds.; CLEUP: Padova, Italy, 2013; pp. 32-52. 